\title{
PPI adverse drugs reactions: a retrospective study
}

\author{
Marco Casciaro ${ }^{1}$, Michele Navarra², Giuseppina Inferrera ${ }^{3}$, Marta Liotta', Sebastiano Gangemi ${ }^{1}$ \\ and Paola Lucia Minciullo ${ }^{1 *}$
}

\begin{abstract}
Proton pump inhibitors (PPIs) are drugs capable of blocking the gastric pump H,K-ATPase in order to inhibit gastric acid secretion. Omeprazole, lansoprazole, pantoprazole, rabeprazole and esomeprazole belong to PPIs category. Although PPIs have a good safety profile, allergic reactions to these molecules can occur. The real rate of hypersensitive reactions to PPIs is unknown. The aim of this retrospective study is to evaluate the rate of hypersensitive reactions to PPIs in patients admitted to our Unit between 2008 and 2013 with a history of drug hypersensitivity. From a database of 1229 patients (921 women, 308 men) with adverse drug reaction we extrapolated the data about PPI reactions. Twelve patients (10 female, 2 men) had a positive history for hypersensitive reaction to PPI. Pantoprazole was the most frequently PPI involved. Based on patient personal history in some cases we performed an oral challenge test for an alternative anti-acid drug and none of them had adverse reactions. According to our experience and according to the literature and pharmacovigilance reports, ADR caused by PPIs are ever increasing. Adverse reactions to these drugs are still under-reported; however, considering the frequency of their prescription worldwide, the risk of severe allergic events is low. Further studies are needed to provide clearer data on the real incidence and prevalence about this matter. This should be useful to help physician in choosing the molecule to prescribe and, in case of hypersensitivity, the alternative molecule to test, also considering the possible cross-reactivity.
\end{abstract}

Keywords: PPI, Proton pump inhibitors, Adverse reaction, Hypersensitivity, Allergy

\section{Introduction}

Proton pump inhibitors (PPIs) are drugs capable of blocking the gastric pump H,K-ATPase in order to inhibit gastric acid secretion [1]. They are used to treat many diseases related to an altered gastrointestinal $\mathrm{pH}$, like peptic ulcers, gastroesophageal reflux disease (GERD), Barrett's esophagus [2]. Omeprazole, lansoprazole, pantoprazole, rabeprazole and esomeprazole belong to PPI category. They undergo a hepatic metabolism and they have no direct toxicity [3]. Although their good safety profile [4], allergic reactions to PPIs can occur. Both immediate and delayed hypersensitivity to PPIs are uncommon $[5,6]$. However, severe, life-threatening immediate reactions,

\footnotetext{
*Correspondence: pminciullo@unime.it

1 School and Unit of Allergy and Clinical Immunology, Department of Clinical and Experimental Medicine, University of Messina, Messina, Italy

Full list of author information is available at the end of the article
}

including anaphylaxis, have been reported [7-16]. The real rate of hypersensitive reactions to PPIs is unknown.

The aim of this retrospective study is to evaluate the rate of hypersensitive reactions to PPIs in patients admitted to our Unit of Allergy and Clinical Immunology between 2008 and 2013 due to a history of drug hypersensitivity.

\section{Methods}

The informed consent was collected from patients and we obtained the consent by our local ethical committee (Prot. 26/16, 15-03-2016). We retrospectively analyzed the data of the patients with a history of drug allergy. It were considered eligible patients admitted to the Allergy and Clinical Immunology Division at the University Hospital of Messina between 2008 and 2013. From a database of 1229 patients (921 women, 308 men) with adverse drug reaction (ADR) we extrapolated the data about PPI reactions. 


\section{Results}

Twelve patients (10 female, 2 men; mean age $46.5( \pm 18.2)$ out of 1229 patients with ADR (1\%) had a positive history for hypersensitive reaction to PPI. Two patients out of 12 were also affected by both allergic rhinitis and

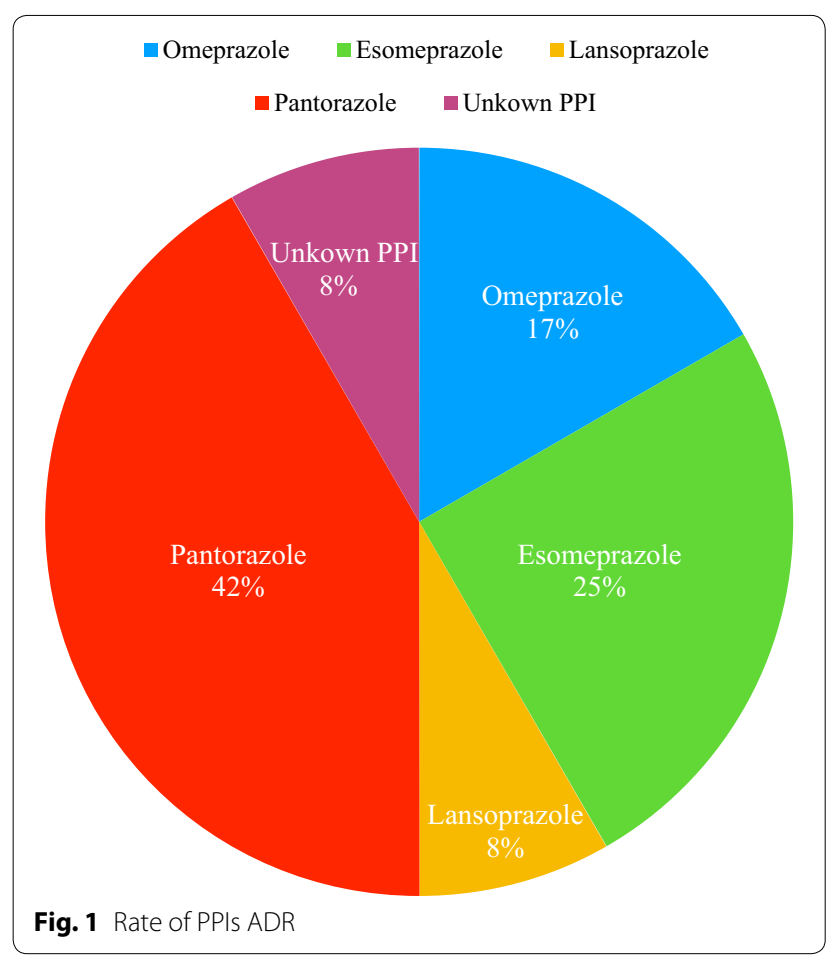

food allergy. 9 subjects have had at least another ADR, 5 of them to a NSAID, 3 to an antibiotic, 2 to an antihypertensive drug. Obviously, the 12 patients have had a diagnosis of GERD or gastritis; the most frequent comorbidity other than the above cited were thyroid dysfunction and essential arterial hypertension. Only 5 of them were in taking other drugs ( 1 patient levothyroxine and an antiplatelet drug, 3 patients anti-hypertensive molecules, and 1 a bisphosphonate drug). Every patient had introduced the PPI as the last molecule in their therapeutic program. On this basis, they re-introduced the other drugs without having ADR apart from the PPI.

Pantoprazole was the most frequent PPI involved in causing reactions ( 5 patients), followed by esomeprazole (3 patients), omeprazole ( 2 patients) and lansoprazole (1 patient); we were unable to identify the exact PPI molecule in one patient (Fig. 1). Table 1 shows the characteristics of patients' clinical data.

The most frequent adverse reaction to PPI were urticaria and urticaria/angioedema. Frequency of signs and symptoms are showed in Fig. 2. Based on patient personal history, we performed an oral challenge test for an alternative anti-acid drug on 5 of them. Three of them were challenged for ranitidine, 1 patient was challenged for lansoprazole and the remaining one for rabeprazole (Fig. 3). None of them had adverse reactions, so all the tests were negative.

Table 1 Case series of adverse drug reactions to PPI

\begin{tabular}{|l|l|l|l|l|l|l|l|}
\hline Drug & Gender & Age & Adverse reaction & Challenge test & Test result & Other diseases & $\begin{array}{l}\text { Multi-drug } \\
\text { intake }\end{array}$ \\
\hline Esomeprazole & F & 44 & Urticaria & - & - & Yes & Yes \\
\hline Esomeprazole & F & 43 & Urticaria & - & - & Yes & Yes \\
Esomeprazole & F & 36 & Urticaria/angioedema & - & No & No \\
\hline Pantoprazole & F & 30 & Urticaria, dispnea & Ranitidine & Negative & No & No \\
\hline Pantoprazole & F & 30 & Urticaria & - & - & Yes & No \\
\hline Pantoprazole & F & 63 & Urticaria/angioedema & Ranitidine & Negative & Yes & Yes \\
Pantoprazole & M & 36 & Urticaria & Lansoprazole & Negative & Yes & No \\
\hline Pantoprazole & M & 21 & Urticaria/angioedema & Ranitidine & Negative & No & No \\
\hline Lansoprazole & F & 77 & Urticaria/angioedema & - & - & Yes & Yes \\
\hline Omeprazole & F & 62 & Urticaria & - & - & Yes & Yes \\
Omeprazole & F & 74 & Angioedema & - & Yes & Yes \\
\hline Unknown PPI & F & 42 & Asthenia, Illness & Rabeprazole & Negative & No & No \\
\hline
\end{tabular}




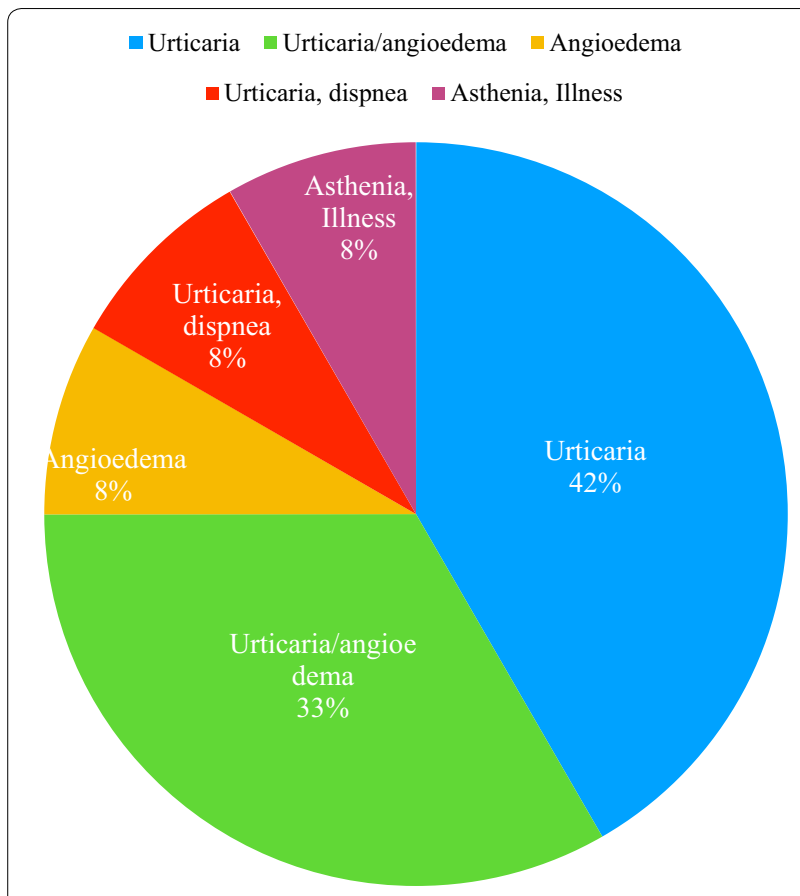

Fig. 2 Signs and symptoms frequency

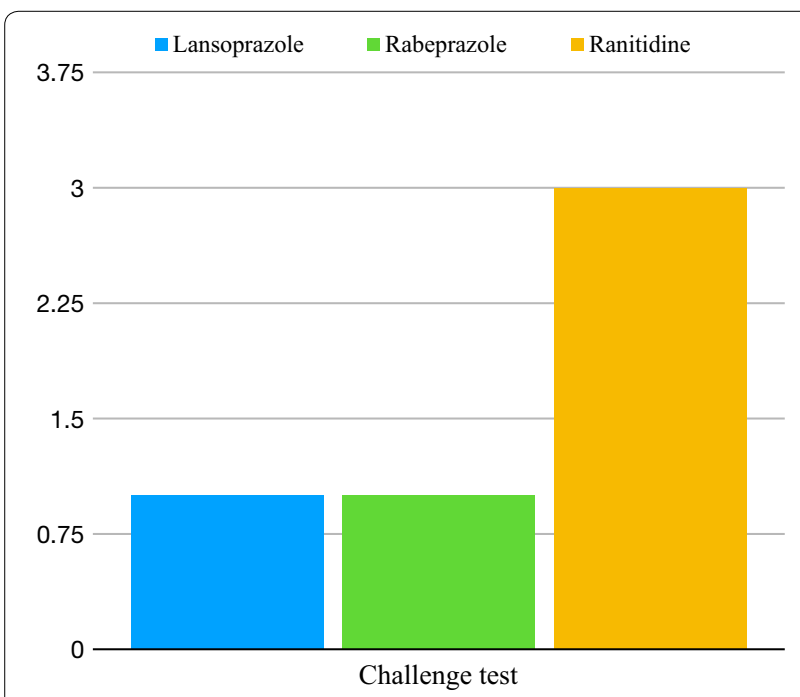

Fig. 3 Alternative drugs tested

\section{Discussion}

An increasing number of reports about allergic reactions against PPIs are present in the literature, starting from 1996 , as previously reported [17].

By spanning the entire literature, it emerged that every PPI molecule can cause allergic reactions [18-22]. The sensitization rate can differ from a study to the other.
In the Food and Drug Administration Adverse Event Reporting System Public Dashboard (FAERS) the adverse reactions to PPIs represent the $0.37 \%$ of the reactions to all the drugs reported from 1989 (when omeprazole was first marketed in the United States) to 2017. These reports include all kinds of adverse events; skin reactions, mainly represented by rash, urticaria, erythema and pruritus, represented the $17 \%$ of all adverse events. The cases of anaphylactic shock reported were 131 , about the $0.24 \%$ of all reactions to PPIs [23].

In 1999, the Uppsala Monitoring Centre database reported 42 cases of anaphylactic reaction to PPIs that constituted the $0.2 \%$ of all the adverse reactions to these drugs. The rate of all anaphylaxis cases was the $0.8 \%$ of adverse reactions to all drugs (Uppsala). These data agree with FAERS data.

In 2008, in the Italian pharmacovigilance network it were reported 123 adverse events caused by PPIs. 9 of these reactions occurred in our region (Sicily). It occurred 1.41 adverse events for every million of PPI packs used in Italy and 0.86 in Sicily [24]. However, the hypersensitive reactions were very low.

Our study analyzed the incidence of hypersensitive events to PPIs over a 6-year period in a group of patients with a history of drug hypersensitivity. Our data showed a higher rate.

In Literature, the most frequent hypersensitivity reactions rate was associated to omeprazole. These reactions ranged from immediate ones, such as urticaria-angioedema and anaphylaxis, to delayed events, such as allergic contact dermatitis and Drug Rash with Eosinophilia and Systemic Symptoms (DRESS) [5, 15, 25-28].

Also in the FAERS database, omeprazole was the main culprit PPI, followed by lansoprazole [23].

In the Italian pharmacovigilance database, in 2008, the most reported PPIs adverse events were to Lansoprazole. In fact, that was the mainly used PPI molecule in that year [24]. A more recent retrospective study identified Lansoprazole as the most frequent PPI in causing anaphylaxis [29]

In the present study Pantoprazole was the most common allergic molecule involved. However, in a previous manuscript, we individuated omeprazole as the most frequent PPI in causing hypersensitive reaction, followed by Pantoprazole [17].

\section{Conclusion}

According to our experience and according to literature and pharmacovigilance reports, ADR caused by PPIs are ever increasing. The data about the hypersensitive rate of each molecule can varies depending on the study considered. The differences are probably due to the historical period considered. In fact, there is a higher rate for the 
older molecules in the less recent studies and an increasing one for new molecules during the last years.

Moreover, it is very difficult to compare the data available because the populations studied are very heterogenic and the cohorts of patients are not comparable. Most studies report only the number of cases of adverse events. On the contrary, the pharmacovigilance database reports the number of cases reported, which are probably underestimated.

Furthermore, spanning Literature we did not find a study similar to our own in order to compare the results.

According to the report of pharmacovigilance, ADR are still under-reported, at least in our region; however, considering the frequency of their prescription worldwide, the risk of severe allergic events is low.

Further studies are needed to provide clearer data on the real incidence and prevalence of hypersensitive reactions to each PPI molecule. Future investigations should be useful to help physician in choosing the best molecule to prescribe and, in case of hypersensitivity, the alternative molecule to test, also considering the possibility of cross-reactions.

\section{Authors' contributions}

SG, MN, Gl: conception and design of the study. MC, ML: interpretation of data. PLM, MC, SG: execution of the study. All authors read and approved the final manuscript.

\section{Author details}

${ }^{1}$ School and Unit of Allergy and Clinical Immunology, Department of Clinical and Experimental Medicine, University of Messina, Messina, Italy. ${ }^{2}$ Department of Chemical, Biological, Pharmaceutical and Environmental Sciences, University of Messina, Messina, Italy. ${ }^{3}$ University Hospital "G. Martino", University of Messina, Messina, Italy.

\section{Acknowledgements}

None.

\section{Competing interests}

The authors declare that they have no competing interests.

\section{Availability of data and materials}

Data and material presented are available in the manuscript and are stored in the Allergy and Clinical Immunology Division at the University Hospital of Messina.

\section{Consent for publication}

All the authors approve the manuscript and gave their consent for publication.

\section{Ethics approval and consent to participate}

After collecting the informed consent from patients and after obtaining the consent by our local ethical committee (Prot. 26/16, 15-03-2016), we retrospectively analyzed the data of patients with a history of drug allergy admitted to the Allergy and Clinical Immunology Division at the University Hospital of Messina between 2008 and 2013

\section{Funding}

This research did not receive any specific grant from funding agencies in the public, commercial, or not-for-profit sectors.

\section{Publisher's Note}

Springer Nature remains neutral with regard to jurisdictional claims in published maps and institutional affiliations.
Received: 27 June 2018 Accepted: 10 January 2019

Published online: 18 January 2019

\section{References}

1. Shin JM, Sachs G. Pharmacology of proton pump inhibitors. Curr Gastroenterol Rep. 2008;10(6):528-34.

2. Iwakiri K, Kinoshita Y, Habu Y, Oshima T, Manabe N, Fujiwara Y, Nagahara A Kawamura O, Iwakiri R, Ozawa S, Ashida K, Ohara S, Kashiwagi H, Adachi K, Higuchi K, Miwa H, Fujimoto K, Kusano M, Hoshihara Y, Kawano T, Haruma K, Hongo M, Sugano K, Watanabe M, Shimosegawa T. Evidence-based clinical practice guidelines for gastroesophageal reflux disease 2015. J Gastroenterol. 2016;51(8):751-67.

3. Robinson $\mathrm{M}$, Horn J. Clinical pharmacology of proton pump inhibitors: what the practising physician needs to know. Drugs. 2003;63(24):2739-54.

4. Thomson AB, Sauve MD, Kassam N, Kamitakahara H. Safety of the long-term use of proton pump inhibitors. World J Gastroenterol. 2010;16(19):2323-30.

5. Pirson F, Geubel A, Marot L. Late hypersensitivity to omeprazole and other proton pump inhibitors. Acta Clin Belg. 2012;67(4):301-3.

6. Otani IM, Banerji A. Immediate and delayed hypersensitivity reactions to proton pump inhibitors: evaluation and management. Curr Allergy Asthma Rep. 2016;16(3):17.

7. Gonzalez P, Soriano V, Lopez P, Niveiro E. Anaphylaxis to proton pump inhibitors. Allergol Immunopathol (Madr). 2002;30(6):342-3.

8. Demirkan K, Bozkurt B, Karakaya G, Kalyoncu AF. Anaphylactic reaction to drugs commonly used for gastrointestinal system diseases: 3 case reports and review of the literature. J Investig Allergol Clin Immunol. 2006;16(3):203-9.

9. Perez Pimiento AJ, Prieto Lastra L, Rodriguez Cabreros MI, Gonzalez Sanchez LA, Mosquera MR, Cubero AG. Hypersensitivity to lansoprazole and rabeprazole with tolerance to other proton pump inhibitors. J Allergy Clin Immunol. 2006;117(3):707-8.

10. Garrido Fernandez S, Cumplido JA, Rabano A, Martinez D, Blanco C, Carrillo T. Allergy to proton pump inhibitors: diagnosis and assessment of cross-reactivity. J Investig Allergol Clin Immunol. 2008;18(2):140-1.

11. Vovolis V, Koutsostathis N, Stefanaki E. IgE-mediated anaphylaxis to proton pump inhibitors_cross-reacting study. Allergy. 2008;63(9):1251-2.

12. Lobera T, Navarro B, Del Pozo MD, Gonzalez I, Blasco A, Escudero R, Venturini M, Alarcon E. Nine cases of omeprazole allergy: cross-reactivity between proton pump inhibitors. J Investig Allergol Clin Immunol. 2009;19(1):57-60.

13. Sobrevia Elfau MT, Garces Sotillos M, Ferrer Claveria L, Segura Arazuri N, Monzon Ballarin S, Colas Sanz C. Study of cross-reactivity between proton pump inhibitors. J Investig Allergol Clin Immunol. 2010;20(2):157-61.

14. Vovolis V, Christogianni K, Koutsostathis N. Immunoglobulin E-mediated anaphylaxis to rabeprazole. J Investig Allergol Clin Immunol. 2010;20(4):360-1.

15. Perez-Ezquerra PR, Morillas LS, Martinez JJ, Fernandez GD, Gomez-Tembleque Mdel P, Alvarez AS, Sanz ML. Anaphylaxis to omeprazole Crossreactivity with the other proton pump inhibitors. Allergol Immunopathol (Madr). 2011;39(1):54.

16. Aksu K, Kurt E. Anaphylaxis to lansoprazole with tolerance to omeprazole. Allergol Immunopathol (Madr). 2012;40(6):393-4.

17. Minciullo P, Isola S, Saitta S, Santoro G, Galati P, Gangemi S. Hypersensitivity to inhibitors of gastric secretion: our experience and review of the literature. Ital J Allergy Clin Immunol. 2008;18:9-14.

18. Chang YS. Hypersensitivity reactions to proton pump inhibitors. Curr Opin Allergy Clin Immunol. 2012;12(4):348-53.

19. Chularojanamontri L, Jiamton S, Manapajon A, Suvanasuthi S, Kulthanan K, Dhana N, Jongjarearnprasert K. Cutaneous reactions to proton pump inhibitors: a case-control study. J Drugs Dermatol. 2012;11(10):e43-7.

20. Bose S, Guyer A, Long A, Banerji A. Evaluation and management of hypersensitivity to proton pump inhibitors. Ann Allergy Asthma Immunol. 2013;111(6):452-7.

21. Ramirez E, Cabanas R, Laserna LS, Fiandor A, Tong H, Prior N, Calderon O, Medrano N, Bobolea I, Frias J, Quirce S. Proton pump inhibitors are associated with hypersensitivity reactions to drugs in hospitalized patients: 
a nested case-control in a retrospective cohort study. Clin Exp Allergy. 2013;43(3):344-52.

22. Ventura MT, Buquicchio R, Cecere R, Calogiuri G, Cannito CD, De Donno M, Maietta G. Anaphylactic reaction after the concomitant intravenous administration of corticosteroids and gastroprotective drugs: two case reports. J Biol Regul Homeost Agents. 2013;27(2):589-94.

23. https://www.fda.gov/Drugs/GuidanceComplianceRegulatorylnforma tion/Surveillance/AdverseDrugEffects/ucm070093.htm. Accessed 30 May 2018

24. http://pti.regione.sicilia.it/portal/page/portal/PIR_PORTALE/PIR_LaStr utturaRegionale/PIR_AssessoratoSalute/PIR_DipPianificazioneStrategi ca/PIR_DPSServizio7News/Report_Inibitori_Pompa_Protonica_I_semes tre_2009.pdf. Accessed 30 May 2018.

25. Al-Falah K, Schachter J, Sasseville D. Occupational allergic contact dermatitis caused by omeprazole in a horse breeder. Contact Dermatitis. 2014;71(6):377-8
26. Bourneau-Martin D, Leclech C, Jamet A, Drablier G, Trenque T, Juengel K, Heath D, Lagarce L, Laine-Cessac P. Omeprazole-induced drug reaction with eosinophilia and systemic symptoms (DRESS). Eur J Dermatol. 2014;24(3):413-5.

27. Sanchez-Morillas L, Rojas Perez-Ezquerra P, Gonzalez Mendiola R, GomezTembleque Ubeda P, Santos Alvarez A, Laguna-Martinez JJ. Eleven cases of omeprazole hypersensitivity: diagnosis and study of cross-reactivity. J Investig Allergol Clin Immunol. 2014;24(2):130-2.

28. Gonzalez-Rubio F, Esteban-Jimenez O, Garces-Sotillos MD, Colas-Sanz C. Anaphylactic shock due to omeprazole. Gastroenterol Hepatol. 2017:40(1):20-1.

29. Kepil Ozdemir S, Oner Erkekol F, Unal D, Buyukozturk S, Gelincik A, Dursun $A B$, Karakaya G, Bavbek S. Management of hypersensitivity reactions to proton pump inhibitors: a retrospective experience. Int Arch Allergy Immunol. 2016;171(1):54-60.
Ready to submit your research? Choose BMC and benefit from:

- fast, convenient online submission

- thorough peer review by experienced researchers in your field

- rapid publication on acceptance

- support for research data, including large and complex data types

- gold Open Access which fosters wider collaboration and increased citations

- maximum visibility for your research: over $100 \mathrm{M}$ website views per year

At BMC, research is always in progress.

Learn more biomedcentral.com/submissions 